\title{
Road construction over voids caused by active gypsum dissolution, with an example from Ripon, North Yorkshire, England
}

Published in Environmental Geology. 2005. Volume 48, 384-394.

DOI 10.1007/s00254-005-1282-6

COLIN J.F.P. JONES ${ }^{1}$

ANTHONY H. COOPER ${ }^{2}$

1. Department of Civil Engineering, Cassie Building, Claremont Road, University of Newcastle upon Tyne, NE1 7RU, UK())

2. British Geological Survey, Keyworth, Nottingham, NG12 5GG, UK

c.j.f.p.jones@ncl.ac.uk

+44(0) 1912227117

+44(0) 1912226888

Abstract

Sudden subsidence problems caused by gypsum karst developed in the Permian sequence of Northern England have caused difficult conditions for road construction. This paper presents the design strategy, mathematical modelling and parameters used to construct roads to cope with such difficult ground conditions. Because it is impossible to locate all the subsidence features along a route, the road design has to cope with potential future problems. This is achieved by using reinforcement comprising layers of tensile membrane material within the earth embankment. This will prevent dangerous catastrophic collapse and maintain serviceability, but will allow sagging to show where major problems exist. The modelling showed that for the situation at Ripon, two layers of tensile membrane material within the earth embankment fulfilled the design brief for the road.

roadconstruction subsidence geotextile tension membrane gypsum karst voids embankment reinforcement 


\section{Introduction}

Gypsum $\left(\mathrm{CaSO}_{4} \cdot 2 \mathrm{H}_{2} \mathrm{O}\right)$ is readily soluble in water and develops karst features much more quickly than limestone, the processes act on a human rather than geological timescale. In places, such as at Ripon in North Yorkshire, the dissolution is so active that a new subsidence feature appears every year or two (Figure 1). Road construction over such gypsiferous deposits has to deal with karst problems including progressive dissolution, sinkhole formation and poor ground conditions caused by collapsed strata or the residue of weak and brecciated strata (Cooper and Saunders, 1999). Building roads over former gypsum mine workings (Cooper 1996) also presents similar conditions. Where gypsum is present in the bedrock, either as massive beds or as veins, it can be associated with sulphate-rich groundwater that may damage concrete, and precautions should be considered (Forster et al., 1995).

The Ripon Bypass was constructed to the east of Ripon. It crosses the Permian sequence which includes approximately 35m of gypsum in the Edlington Formation (formerly the Middle Marl) and 10m of gypsum in the higher Roxby Formation (formerly the Upper Marl). These two gypsum sequences rest on two limestone aquifers, the Cadeby Formation (formerly the Lower Magnesian Limestone) and the Brotherton Formation (formerly the Upper Magnesian Limestone) respectively. The dolomitic limestone escarpments act as catchment areas and the water percolates down-dip into the gypsiferous sequences, before flowing into a major buried valley along the line of the Rive Ure (Cooper, 1986, 1995, 1998). Complex cave systems have developed in the gypsum, and artesian, sulphate-rich springs are locally present. Because of the thickness of gypsum the caves are large and surface collapses up to $30 \mathrm{~m}$ across and $20 \mathrm{~m}$ deep are present in some parts of the subsidence belt (Figure 2). However, along the line of the Ripon by-pass individual new collapses tend to be around $10 \mathrm{~m}$ or less in diameter though these commonly grow into larger depressions by the failure of the subsidence hollow sides. The subsidence is not random, but occurs in a reticulate pattern related to the jointing in the underlying strata (Figure 1; Cooper, 1986). Unfortunately, it is impossible to predict where the next subsidence event will occur. Around Ripon, a significant subsidence occurs approximately every year or two (Cooper, 1995). The dates of the subsidence events show that some areas are more active than others, especially areas bounding the Ure valley where cave water flows into 
the buried valley gravels. The new Ripon Bypass passed close to several subsidence hollows and crossed a very active area of gypsum dissolution.

The desk study for the Ripon Bypass included an assessment of the likely magnitude and frequency of the subsidence events along the route of the road. Resistivity tomography was also undertaken on the Ure Bridge site, but the results were inconclusive and no additional subsidence features were pinpointed. A costly investigation of closely spaced boreholes could have been undertaken, but it is very difficult to locate individual cavities with boreholes. It is also impractical to grout cavities in such a gypsiferous area because of their large size and water flow. In addition, filling them may cause accelerated dissolution in the adjacent ground aggravating the subsidence problems with the possibility of litigation.

\section{Design strategy}

The development of surface voids caused by evaporite dissolution of the underlying strata is largely unpredictable in both time and location. In some places, the prediction of subsidenceprone areas can be attempted based upon spatial and historical evidence, but the results are uncertain and difficult to verify. From an engineering perspective the development of randomly occurring voids is a major potential hazard that poses particular structural problems. The logical approach to the development of surface voids is to avoid the problem by relocating the particular structure to an area not affected. This may be possible with some structures but it is usually impossible to use this strategy with basic infrastructure such as transportation systems. In these cases, design precautions are required.

In the case of individual structures conventional ground investigation techniques can be used to establish the presence of a void in the immediate vicinity of the building. If necessary extensive precautions such as deep piling and raft foundations can be constructed to provide against uncontrolled settlement or sudden collapse. Where construction covers a wide area, as in the case of a highways system or waste disposal facility, detailed site data of the entire site is not possible and the development of voids must be expected. In these cases, the widespread use of 
comprehensive structural foundations (such as deep piling) is uneconomic and other precautions have to be considered.

The design approach is to consider two limit states, covering ultimate and serviceability conditions. The ultimate limit state considers collapse conditions whilst the serviceability limit state governs deformation modes of failure which do not lead to collapse but which render the structure or any system supported by the structure unserviceable, Figure 3.

With the development of voids in excess of 10-20 m wide it may not be possible to design against the ultimate limit case. In this case, collapse of the structure is inevitable and any structural precautions are restricted to providing warning of the collapse in order that loss of life may be avoided and, if necessary, to permit the mobilisation of emergency measures. Typically the design objective in this case is to provide a safe period of 24 hours from loss of serviceability to total collapse. In the case of small voids (1-8m diameter) the design objective is to retain long term serviceability.

\section{Design solutions}

The use of basal reinforcement to prevent collapse of fill following the formation of a void is becoming an accepted foundation engineering technique. Two examples of the use of this technique are shown in Figure 4. The first example, Figure 4(a), shows the use of reinforcement to prevent the collapse of an embankment into a foundation void in a transportation-related application. In this application, the reinforcement also may be required to ensure the surface of the embankment remains in a serviceable condition. The design allows for serviceability of the road to be maintained for voids up to $8 \mathrm{~m}$ in diameter and distortion and subsidence of the road to occur for in excess of $10 \mathrm{~m}$ in diameter.

The second example, Figure 4(b), shows the use of reinforcement to prevent distress in the basal liner system of a landfill when differential settlements occur beneath the liner, caused by the formation of a void at depth resulting from evaporite dissolution. In such a situation, a risk 
assessment of the consequences of failure and pollution risk to local aquifers should also be considered.

While the two applications shown in Figure 4 are identical from the viewpoint of the role of the reinforcement, there is a fundamental difference between them. In the case of the transportationrelated application (Figure 4(a)) the reinforcement is required to restrict the amount of deformation at the surface of the embankment at a height above the level of the reinforcement, whereas in the landfill-related application (Figure 4(b)) the reinforcement is required to restrict the amount of deformation in the liner system adjacent to the reinforcement. The need to maintain serviceability at a distance above the level of the reinforcement in the basal reinforced embankment application makes the analysis of this problem more complex than the landfillrelated case.

The development of basal reinforcement is an example of the technical and economic benefits which have been provided by the introduction of high strength polymeric materials for use in reinforced soil, Jones (1996). Currently available geosynthetic reinforcement can be categorised as being stiff materials typically formed using high strength fibres (polyester or aramid) with ultimate tensile strength $\geq 12,000 \mathrm{kN} / \mathrm{m}^{2}$, or extensible materials typically formed from molecular orientated high density polyethylene (HDPE) having tensile strength in the range $2-4,000 \mathrm{kN} / \mathrm{m}^{2}$. Examples of the performance properties of these proprietary materials and similar products are provided by Jones (1996).

The analytical models developed for basal reinforcement design use the concept of producing a load transfer platform. This platform is designed according to whether high strength (stiff) or medium strength reinforcement is used. In the former case, the design frequently uses a tension membrane which supports the overlying fill and loads, with or without the development of a supporting arch in the overlying fill. In the case of extensible medium strength reinforcement, multiple layers of reinforcement are used to develop the necessary tensile strength assuming that the multiple layers of reinforcement also provide an improved soil arch over the void (Jenner $e t$ al., 1998). 


\section{Analytical procedures}

Current methods of design of tension membranes adopt a conservative approach because of the uncertainties involved and the simplicity of the analytical techniques used. The soil and reinforcement are assumed to be resting initially on a firm foundation. The development of a void under the reinforcement results in the overlying soil deflecting into the void. The deflection of the soil layer generates arching within the soil above the reinforcement and the load in the reinforcement over the void is less than the theoretical weight of the soil above the void.

Deflection of the reinforcement into the void mobilises part of the reinforcement strength and the material will act as a tension membrane supporting loads normal to the plane, Figure 5. As a result of the reinforcement straining three cases can be considered;

i) the soil-reinforcement system fails, Figure 5(a)

ii) the soil-reinforcement system exhibits limited deflection and the system bridges the void, Figure 5(b)

iii) the soil reinforcement deflects until the reinforcement comes in contact with the bottom of the void. In this case, part of the load is transmitted to the bottom of the void and the tension in the reinforcement is reduced, Figure 5(c).

The case illustrated in Figure 5(a) represents failure and a deficient design. The case illustrated in Figure 5(b) represents the classical design case for construction over a void and the basis of the modelling presented here. The case illustrated in Figure 5(c) is not typical for voids caused by gypsum dissolution. However, its characteristics could be modelled like that where reinforcement is used to spread the load of embankments or soil structures on support piles a scenario not considered here, but described by (Jones et al., 1990).

Assuming that the reinforcement spanning a void transmits tensile stresses but not shear stresses and that the soil-reinforcement interface above the void is frictionless, the applied stress to the membrane is normal. For plane strain conditions the shape of the membrane is circular. 
Arching above the void may cause a reduction in vertical stress. In the case of a void under a fill, arching reduces the stress and the tension in the reinforcement spanning the void by transferring part of the stress to adjacent stable ground. Approximate methods for calculating the vertical stress on a horizontal plane at the base of a soil mass due to yielding of part of the base were discussed by Terzaghi (1943), Kezdi (1975) and Bonaparte and Berg (1987), Figure 6.

The tension membrane theory is used in British Standard BS 8006 (Anon, 1995) for construction over voids. It assumes that the deflected shape of the reinforcement is circular, however, the weight of the fill acting on the reinforcement over the unsupported void causes the membrane to deform into the shape of a catenary. To simplify the analysis BS 8006 (Anon, 1995) assumes that the load is distributed along the horizontal span of the reinforcement rather than along the deflected length. In this case, the shape of the deflected reinforcement is parabolic. The assumptions made with respect to the actual situation compared to the design condition in BS 8006 are shown in Figure 7.

\section{Validity of current methods}

The BS8006 (Anon, 1995) method was developed by Jones et al (1990) and is acknowledged as being conservative. This is a consequence of the simplicity of the method which ignores many of the soil parameters involved in the analytical problem.

An advance on the BS8006 (Anon, 1995) method would be to couple arching theory with tension membrane theory as described by Giroud et al (1990). The resulting analytical problem is one of complex soil-reinforcement interaction and the solution provided involves uncoupling the soil response due to arching from the reinforcement response associated with the tension membrane theory. Consequently, a two-step approach is used. Firstly, the behaviour of the soil fill is analysed using classical arch theory; this provides pressure at the base of the soil layer on that portion of the reinforcement located above the void. Secondly, tension membrane theory is used to establish a relationship between the pressure on the reinforcement, the tensile stress and strain in the reinforcement and the deflection. An inherent assumption in this uncoupled two-step approach is that the deformation required to generate a soil arch is compatible with a tensile strain required to mobilise the reinforcement tension. However, this has not been verified. 
Experimental tests indicate that the tension membrane theory can be considered to be a lower bound conservative estimate of soil-reinforcement behaviour (Fluet et al, 1986). The theory appears to describe accurately the condition where a void exists prior to construction. Where a void is occurs after construction, the existing theories for analysing soil-reinforcement supporting an embankment are inaccurate and over-conservative. It can be concluded that accurate analysis of any reinforcement system supporting an embankment over a void produced by evaporite dissolution needs to consider both the geometry of the problem and the materials. The proper evaluation of the material properties must consider the reinforcement, the overlying fill, the subsoil support conditions and their combined behaviour. This can best be achieved using continuum methods of analysis.

\section{Modelling the design problem for voids caused by evaporite dissolution}

\section{Void geometry}

The successful modelling of any reinforced soil structure spanning a void can only be achieved if the parameters used in the analysis are accurately described. It is essential to determine the size of any potential void. The selection of unrepresentative void dimensions will result in the analysis of an impossible or improbable problem. The majority of subsurface dissolution features migrate upwards to produce circular or elliptical depressions at the surface. The void sizes can vary enormously from 1 to 40 metres or more. Elsewhere, the latter was the size of the sinkhole that occurred under the Vera Cruz road in Pennsylvania in 1983 causing the collapse of a bridge (Bonaparte and Berg, 1987). The majority of sinkhole occurrences are smaller than this.

\section{Surface geology}

The surface geology can have a significant effect on both the development of a void and the behaviour of any reinforcement used to support a fill over a void. Two geometries can be 
identified, the first being where rock supports the fill directly, and the second where a soil layer exists beneath the reinforcement. In both cases the analytical model is required to describe accurately the material properties of the supporting soil or rock.

\section{Parameter values}

The height and material properties of the fill supported by a reinforcing member will influence the reinforcement/soil performance and in any modelling exercise realistic material properties of any fill material are required. Use of layered fills may influence the behaviour and accordingly care has to be taken to describe the geometry of any structure. However, unlike many reinforced soil modelling problems, modelling the actual construction process is not necessary and a realistic solution can be obtained by modelling the effects of increased gravity.

The symbols and abbreviations used in the following descriptions, diagrams and models are: Friction - $\phi^{\prime}$, Cohesion - c', Dilation - $\psi$, Bulk modulus - $K^{\prime}$, Shear modulus - $G^{\prime}$, Density - $\gamma$, Tensile strength - $T$, Void diameter - D, Vertical displacement - $d$, Stiffness - $J$, Embankment height $-H$,

\section{Reinforcement orientation}

Reinforcement over a void may be required in either a single direction, as in the case of a long slender void such as a trench, or in two directions, when the void is either circular or an irregular shape. In the first case reinforcement with anisotropic strength characteristics are efficient. In the latter, strength in two dimensions is required. This may be achieved using grid reinforcement, individual fabric reinforcement, or at least two layers of strip reinforcement laid orthogonally. 


\section{Factors affecting the structural performance of reinforced fills spanning voids}

The factors affecting the performance of reinforced fills spanning voids include: the size of the void, the immediate surface geometry (i.e. rock or soil - the latter results in a larger void, all other factors being equal), the number of layers, stiffness and strength of the reinforcement, the height of the fill above the reinforcement and its stiffness.

For serviceability the maximum allowable differential deformation at the surface has to be defined, this is $d_{s} / D_{s}$ where $d_{s}$ is the vertical displacement and $D_{s}$ the diameter of the subsidence area (Figure 7). In the case of highways, $\left(d_{s} / D_{s}\right)$ is taken to be less than or equal to $1 \%$ for high speed roads, or equal to $2 \%$ for other roads, (Parry, 1983). In the case of high speed railways (i.e. travelling at $300 \mathrm{kph}$ ), the allowable differential deformation can be limited to $0.002 \%$. This tolerance can only be achieved if the embankment over the reinforcement membrane is very stiff such as that formed with a cement stabilised layer (Ast et al., 2001). Greater values of $\left(d_{s} / D_{s}\right)$ may be acceptable depending on the restrictions placed on the permissible differential settlement.

\section{Effect of reinforcement stiffness on surface differential deformation}

A common view of the role of the reinforcement in preventing embankment collapse is that the stiffer the reinforcement the lower the differential deformation $\left(d_{s} / D_{s}\right)$ at the surface. Consequently, reinforcement stiffness is considered to have a fundamental effect on serviceability. Figure 8 shows the results of a parametric study relating to this aspect, where the conventional frictional fill $\left(\phi^{\prime}=35^{\circ}, \mathrm{c}^{\prime}=0, \gamma=20 \mathrm{kN} / \mathrm{m}^{2}\right)$ is used to form the embankment.

In Figure 8(a) the surface differential deformation $\left(d_{s} / D_{s}\right)$ is plotted against reinforcement stiffness $J$ and the height to diameter $(H / D)$ ratio, which defines the problem geometry for a void diameter $\mathrm{D}$ of $1 \mathrm{~m}$. The results show clearly that $H / D$ ratio has a major effect on reducing surface differential deformation with reinforcement stiffness having a relatively minor secondary effect. Increasing the $H / D$ ratio increases the amount of arching in the embankment fill, especially for $H / D$ ratios greater than 1.5 . The increased arching reduces the surface differential deformation 
significantly. Conversely, a relatively large increase in reinforcement stiffness is required to significantly reduce the surface differential deformation.

Figure 8(b) shows the same parameters plotted but for a void diameter where $D=4 \mathrm{~m}$. The results are very similar to the $1 \mathrm{~m}$ diameter void case shown in Figure 8(a). Of particular note is the similarity in magnitude of the $H / D$ ratios for the same $\left(d_{s} / D_{s}\right)$ plots. Thus, void diameter, as a singular parameter, has only a minor influence on surface differential deformation when $H / D$ ratios are also used as the basis for defining the problem geometry.

Figure 8c) shows the same parameters plotted for void diameters less than or equal to $8 \mathrm{~m}$. Regions of different surface differential deformation are readily identified according to $H / D$ ratio and reinforcement stiffness. $H / D$ ratio has a dominant effect on surface differential deformation with reinforcement stiffness having a secondary effect.

From the results shown in Figure 8 it is observed that serviceability solutions in terms of values of $\left(d_{s} / D_{s}\right)$ can be obtained by using unique combinations of both $H / D$ ratio and reinforcement stiffness. Reinforcement stiffness alone may not provide the required degree of serviceability.

\section{Effect of reinforcement stiffness on reinforcement load}

Use of the various analytical models available, e.g. BS 8006 (Anon, 1995), Giroud et al (1990), suggests that the load carried by the reinforcement is in proportion to its stiffness. Thus, very stiff reinforcements would attract very high loads compared to less stiff reinforcements. The results of a parametric study using well graded coarse-grained (cohesionless) fill over the reinforcement is shown in Figure 9.

Figure 9(a) shows the relationship between reinforcement stiffness and reinforcement load for various $H / D$ ratios at a void diameter $D=4 \mathrm{~m}$. The results show an increase in load carried by the reinforcement for $H / D$ ratios increasing from 0.5 to 1.5 where it reaches a maximum. For 1.5 $<H / D<3.0$ there is a reduction in load carried by the reinforcement, and for $H / D \geq 3.0$ the load carried by the reinforcement is constant. These results are consistent with those obtained from 
arching theory where the maximum vertical stress at the base of an arching soil occurs at $H / D \approx$ 1.5 .

Figure 9(a) also shows the effect of the reinforcement stiffness on load carried by the reinforcement for void diameter $\mathrm{D}=4 \mathrm{~m}$. Up to a reinforcement stiffness approximating 2,000 $\mathrm{kN} / \mathrm{m}^{2}$ the reinforcement load is proportional to reinforcement stiffness. However, for reinforcement stiffnesses greater than $2,500 \mathrm{kN} / \mathrm{m}^{2}$ increases in reinforcement load are no longer proportional and are relatively small compared to the increase in reinforcement stiffness.

The plots shown in Figure 9(a) may be divided into two regions; a strength constrained region and a stiffness constrained region. These are shown in Figure 9(b) for $H / D=1.5$, yielding the maximum reinforcement load, and void diameter $\mathrm{D}=4 \mathrm{~m}$. In the strength constrained region, reinforcement load is proportional to reinforcement stiffness, and defines the reinforcement strength/stiffness relationship used in the analyses. In the analyses the relationship of reinforcement stiffness to tensile strength $(J=10 T)$ was used. In the stiffness constrained region reinforcement load is not proportional to reinforcement stiffness and increases much more slowly. In this region specific combinations of reinforcement stiffness and reinforcement load may be chosen to satisfy a given set of structural performance criteria. The intersection of the strength constrained and the stiffness constrained regions is the minimum possible load that is carried by the reinforcement for a specific problem geometry and reinforcement type.

Figure 9(c) contains plots of reinforcement load versus reinforcement stiffness at $H / D=1.5$, yielding the maximum reinforcement loads, and void diameters $D \leq 8 \mathrm{~m}$. The reinforcement strength constrained boundary adhering to $J=10 T$ is also plotted. As would be expected the larger the void diameter the higher the load carried by the reinforcement. While changes in the $H / D$ ratio has an effect on reinforcement load (see Figure 9(a)), but this is relatively small compared to the influence of void diameter. For simplicity, a conservative reinforcement load based on a $H / D$ ratio of 1.5 may be assumed for most problem geometries and void diameters. 


\section{Effect of multiple reinforcement layers on structural performance}

It has become fairly common practice to include multiple layers of reinforcement in order to fulfil the load carrying requirements. However, in doing this little attention is paid to the overall stiffness requirements of the basal reinforcement. Figure 10 shows the results of a parametric study relating to this aspect.

In the parametric study the relationship between reinforcement stiffness and reinforcement strength was maintained at $J=10 T$, which is consistent with practice inasmuch as when lower strength reinforcements are used their stiffnesses are invariably reduced proportionately. When modelling the effect of multiple reinforcement layers equivalent gross reinforcement strengths were maintained. For example, two layers of reinforcement had half the strength per reinforcement layer compared to a single layer of reinforcement and three layers of reinforcement had one third the strength per reinforcement layer compared to a single layer of reinforcement. Because of the maintenance of $J=10 T$ throughout, this same relationship applies to reinforcement stiffness. Thus, a reinforcement having half the strength of another reinforcement will also have half the stiffness. A constant vertical spacing of $300 \mathrm{~mm}$ was used between adjacent reinforcement layers in all cases.

Figure 10(a) shows the sum of the reinforcement loads for multiple reinforcement layers at various $H / D$ ratios and a void diameter $D=4 \mathrm{~m}$. Where the single layer of reinforcement is used the load carried by the reinforcement rises to a maximum at $1.5<H / D<2$ and then reduces to a constant value for $H / D \geq 3$. This trend is identical to that shown in Figure 9(a). Where multiple layers of reinforcement are used the sum of the reinforcement loads increase to a maximum at $H / D$ ratios. This difference in shape of the load curves is thought to be due to the difference in stress distribution caused by the presence of the multiple reinforcement layers within the embankment fill.

As expected, the stiffer single reinforcement layer attracts a greater total load than the less stiff multiple reinforcement layers, although the total reinforcement loads are identical for $H / D \geq 3$. Where multiple reinforcement layers have been used the total reinforcement load is consistent, 
i.e. the two, three and six layers of reinforcement shown in Figure 10(a) all exhibit similar total reinforcement loads over the range of $H / D$ ratios. Also, where multiple reinforcement layers have been used the tensile load in the bottom reinforcement layer is always greater than in the top layer, although the magnitude of the difference changes depending on the magnitude of the $H / D$ ratio.

Figure 10(b) shows the effect of multiple reinforcement layers on surface differential deformation. The results show clearly that the stiffer single reinforcement layer reduces the surface differential deformation compared to the less stiff multiple reinforcement layers. The magnitude of the difference varies according to the $H / D$ ratio, but for $H / D \leq 1.5$ the differences are significant.

Comparison of the results in Figure 10(b) with those in Figure 8(b) show that multiple reinforcement layers have the same effect on surface differential deformation as a single reinforcement layer of the same stiffness. Thus, no additional improvement in surface differential deformation is gained when using multiple reinforcement layers.

\section{Conclusions}

The use of basal reinforcement to maintain the performance of fills spanning voids can be an effective construction technique, particularly if the void, or voids, have a diameter $<10 \mathrm{~m}$. The design problem involves a complex interaction between fill/foundation properties, fill/void geometry and reinforcement properties. The analysis of this problem is best performed by continuum methods especially where serviceability criteria are to be considered.

Reinforcement stiffness has a limited effect in reducing the differential deformation at the surface of the embankment. The dominant factor influencing the surface differential deformation is the $H / D$ ratio which denotes the degree of arching present. Reinforcement stiffness has a secondary effect on surface differential deformation and relatively large increases in reinforcement stiffness are required to reduce the surface differential deformation 
significantly. Solutions that limit surface differential deformation must contain unique combinations of both $H / D$ ratio and reinforcement stiffness.

Because of the complex interaction between embankment fill and reinforcement spanning a void, the load carried by the reinforcement is not in proportion to its stiffness. Unlike the more conservative analytical models, continuum methods provide a more accurate means of assessing reinforcement loads that satisfy given performance criteria.

Multiple reinforcement layers may be used as a means of carrying the reinforcement loads. However, the stiffness of the multiple reinforcement layers has the same effect on serviceability as a single reinforcement layer of the same stiffness.

\section{Acknowledgements}

North Yorkshire County Council Road Construction Unit is thanked for permission to publish construction details of the Ripon Bypass. Dave Entwisle and Pete Hobbs are thanked for reviewing the manuscript. AHC publishes with permission of the Director, British Geological Survey (N.E.R.C.). The authors acknowledge the contribution made towards this work by the ROSES (Risk of Subsidence due to Evaporite Solution) Project: ENV4-CT97-0603 and IC20-CT97-0042 funded by the EU Framework IV Programme. Also thanked are Professor Paul Younger and Dr John Lamont-Black for organising the ROSES research programme.

\section{References}

Ast W, Hubal H, Schollmier P. 2001. Bewehrter Erdkorper mit Endfall-Warnanlage fur den Eisenbahnknoten Grobers Sonderweroffentlichang der Eisenbahntechnischen Rundschau, Edition ETR. Ingenieurbauwerke S130-136

Bonaparte, R and Berg, R R. 1987. The use of geosynthetics to support roadways over sinkhole prone areas. pp 427-445 in Beck, B F and Wilson, W L (eds) Karst hydrogeology; engineering and 
environmental applications. Proceedings of the Second Multidisciplinary Conference on Sinkholes and the Environmental Impacts of Karst. Orlando/Florida/9-11 February 1987. A A Balkema, Rotterdam.

Anon, 1995. BS 8006, Code of Practice of Strengthened/Reinforced Soils and Other Fills. British Standards Institution.

Cooper, A H. 1986. Foundered strata and subsidence resulting from the dissolution of Permian gypsum in the Ripon and Bedale areas, North Yorkshire. pp.127-139 in Harwood, G M and Smith, D B (eds). The English Zechstein and related topics. Geological Society of London, Special Publication. No. 22.

Cooper, A.H. 1995. Subsidence hazards due to the dissolution of Permian gypsum in England: investigation and remediation. pp. 23-29 in Beck, F.B. (ed.) Karst Geohazards: engineering and environmental problems in karst terrane. Proceedings of the fifth multidisciplinary conference on sinkholes and the engineering and environmental impacts of karst Gatlinburg/Tennessee/2-5 April 1995. 581pp. A.A.Balkema, Rotterdam.

Cooper, A.H. 1996. Gypsum: geology, quarrying, mining and geological hazards in the Chellaston area of South Derbyshire. British Geological Survey Technical Report WA/96/30, Keyworth, Nottingham.

Cooper, A.H. 1998. Subsidence hazards caused by the dissolution of Permian gypsum in England: geology, investigation and remediation. In Maund, J.G. \& Eddleston, M (eds.) Geohazards in Engineering Geology. Geological Society, London, Engineering Special Publications, 15, pp. 265-275.

Cooper, A.H. and Saunders, J.M. 1999. Road and bridge construction across gypsum karst in England. In Beck, B.F., Pettit,A.J. and Herring.J.G. Hydrogeology and Engineering Geology of Sinkholes and Karst1999. Proceedings of the Seventh Multidisciplinary Conference on Sinkholes and the Engineering and Environmental Impacts of Karst. Harrisburg/Hershey, Pennsylvania, April 10-14, 1999. A.A.Balkema, Rotterdam, pp. 407-411.

Fluet, J E, Christopher, B R and Slater, A R. 1986. Geosynthetic stress-strain response under embankment loading conditions. Proceedings of the $3^{\text {rd }}$ International Conference on Geotextiles, Vienna, 1, pp.175-180. 
Forster, A, Culshaw, M G and Bell, F G. 1995. Regional distribution of sulphate rocks and soils of Britain. 95-104 in Eddleston, M., Walthall, S., Cripps, J.C. and Culshaw, M.G. (eds) Engineering Geology of Construction. Geological Society Engineering Geology Special Publication No10.

Giroud, J P, Bonaparte, R, Beech, J F and Gross, B A. 1990. Design of soil layer-geosynthetic systems overlying voids, Geotextiles and Geomembranes, Elsevier, 9, pp.11-50.

Jenner, C G, Austin, R A and Buckland, D. 1998. Embankment support over piles using geogrids. Proceedings of the $6^{\text {th }}$ International Conference on Geosynthetics, pp.763-766, IFAI, Atlanta.

Jones, C J F P. 1996. Earth Reinforcement and Soil Structures. Thomas Telford, 357pp.

Jones, C J F P, Lawson, C R, Ayres, D J. 1990. Geotextile reinforced piled embankments. Geotextiles, Geomembranes and Related Products, Den Hoedt (ed.), Balkema, Rotterdam, pp.157-159.

Kezdi, A .1975. Lateral earth pressure. pp 147-220 in Winkerton and Fang (eds.) Foundation Engineering Handbook, Van Nostrand Reinhold Company, New York.

Lawson, C R, Jones, C J F P, Kempton, G T and Passaris, E K S. 1994. Advanced analysis of reinforced fills over areas prone to subsidence. Proceedings of the $4^{\text {th }}$ International Conference on Geosynthetics, Singapore, 1, pp.311-316.

Parry, H J. 1983. Coping with Fife's mining industrial heritage. Municipal Engineer, 110, 778, pp.231240.

Terzaghi, K. 1943. Theoretical Soil Mechanics, John Wiley \& Sons, New York.

Figure 1. The mapped subsidence areas caused by gypsum dissolution in the vicinty of Ripon in North Yorkshire. The subsidence hollows are shown in black with the dates of the subsidence where known. The urban area is shown with a horizontal stipple. 
Figure 2. Cross-section from south-west to north-east across the Ure Valley near the northern end of the Ripon Bypass showing the development of subsidence breccia pipes emanating from the two sequences of gypsum and causing subsidence features at the surface.

Figure 3. Limit states for basal reinforcement over voids

Figure 4. Use of reinforcement to span voids

Figure 5. Action of reinforcement spanning a void

Figure 6. Theoretical reduction in vertical stress due to cohesionless soil arching over an infinitely long void of width $b(m)$ or a circular void of diameter $\mathrm{D}(\mathrm{m})$

(After Giroud et al, 1990)

Figure 7: Tension membrane theory

(a) assumed working condition - arching action assumed in determining tension in reinforcement

(b) actual working condition - arching action assumed

(c) ultimate condition - no arching action

Figure 8. Effect of reinforcement stiffness on surface differential deformation

(After Lawson et al, 1994)

Figure 9. Effect of reinforcement stiffness on reinforced load

Figure 10. Effect of multiple reinforcement layers on structural performance for void diameter $\mathrm{D}=4 \mathrm{~m}$ 


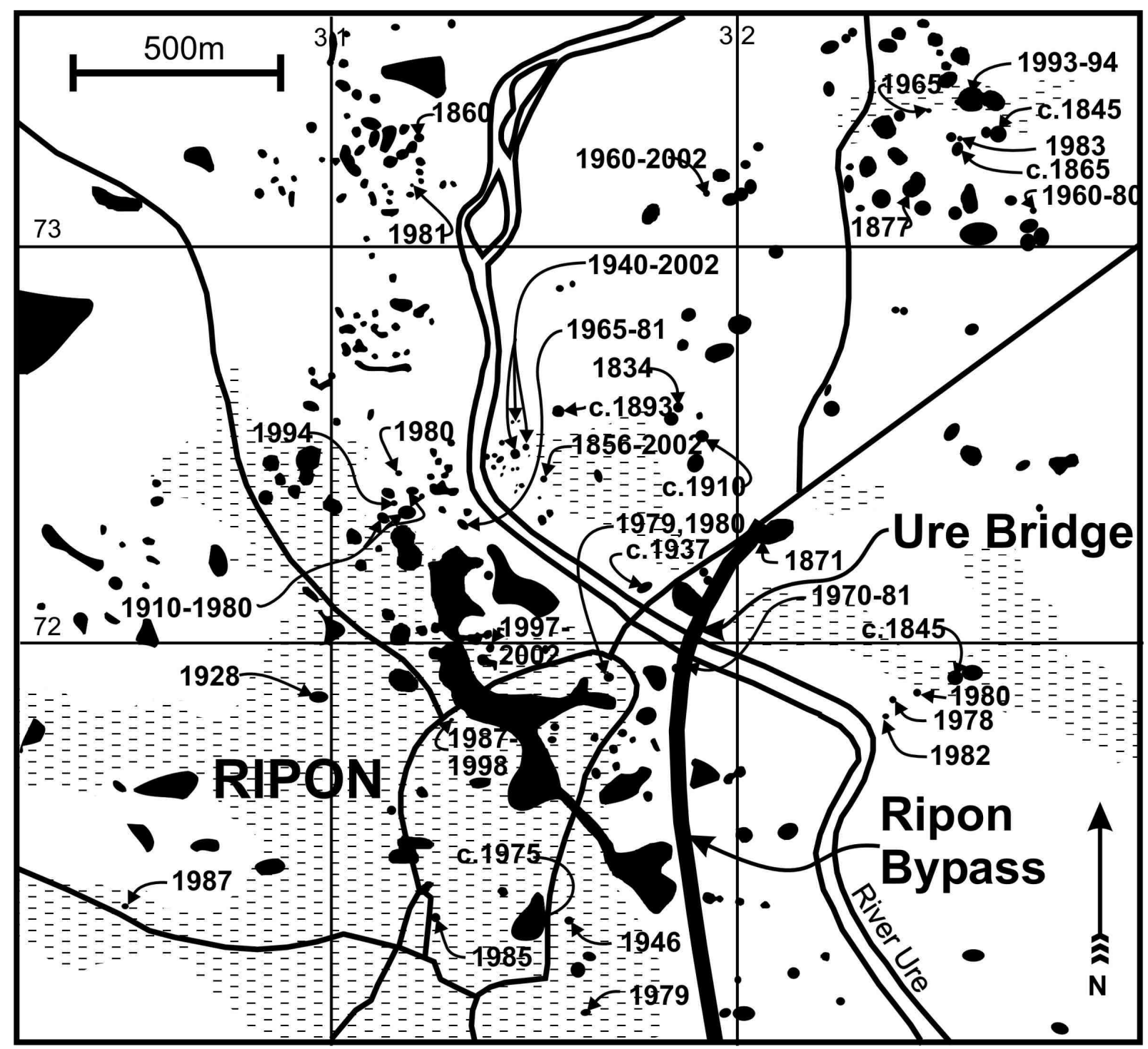

Figure 1. The mapped subsidence areas caused by gypsum dissolution in the vicinty of Ripon in North Yorkshire. The subsidence hollows are shown in black with the dates of the subsidence where known. The urban area is shown with a horizontal stipple. 


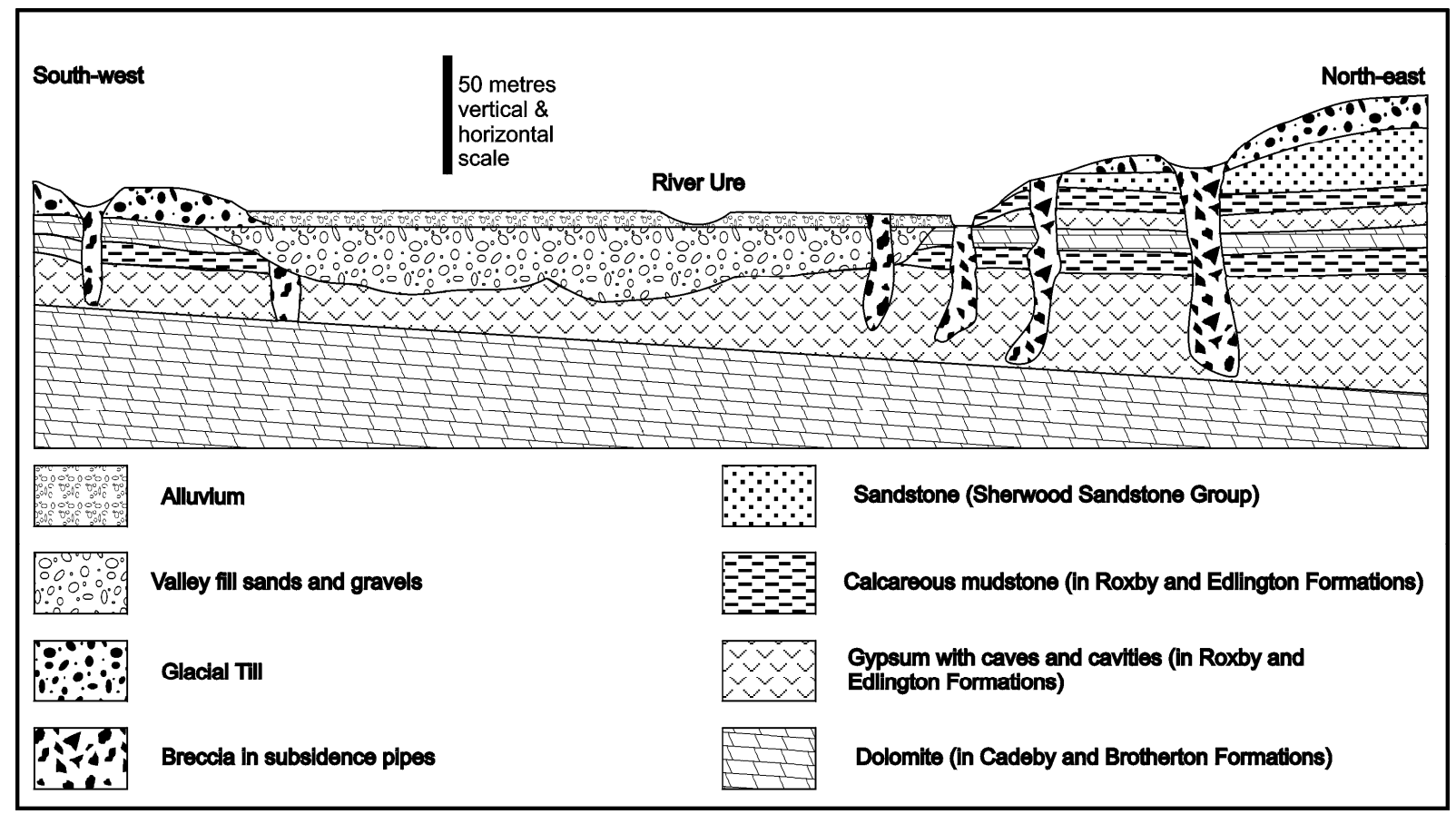

Figure 2. Cross-section from the south-west to the north-east along the line of the Ripon Bypass and the Ure Bridge. The section illustrates the presence of dissolution in the gypsum sequences with the collapse of the overlying strata resulting in subsidence hollows and pipes at the surface. The gypsum also contains numerous cavities and caves, which have not been illustrated. The section is approximately two kilometres long with a vertical exaggeration of about five times. 


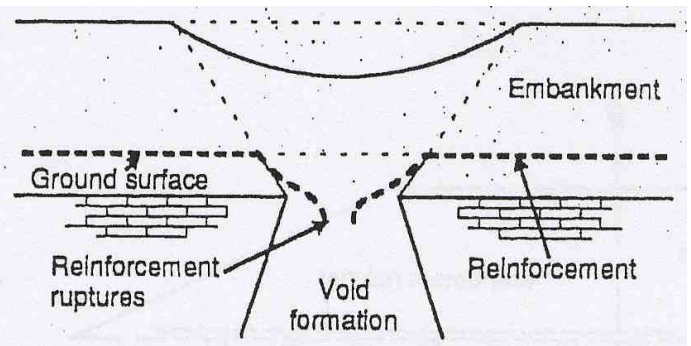

(i) Rupture of reinforcement

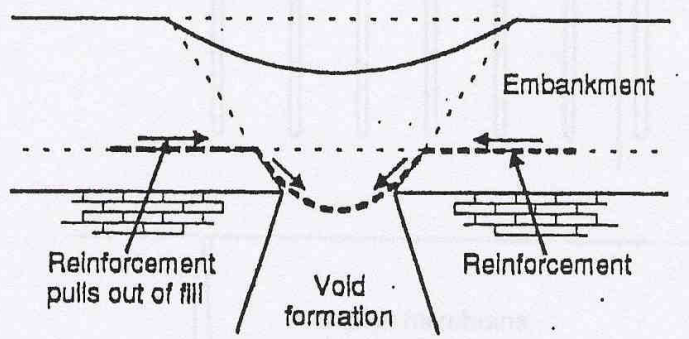

(ii) Reinforcement bond failure

a) Ulimate limit states

Surface deforms but serviceablity is malntainod

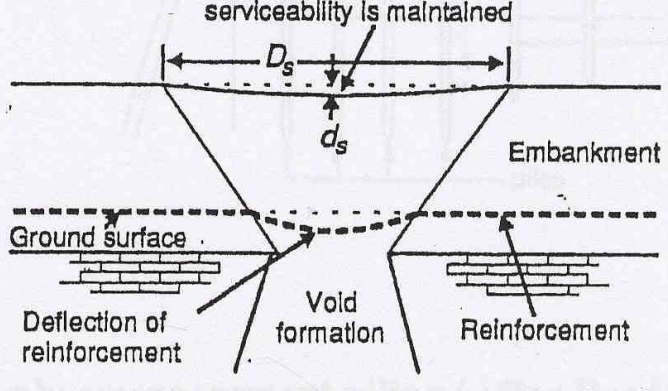

b) Serviceability ilmit state

Figure 3. Limit states for basal reinforcement over voids 


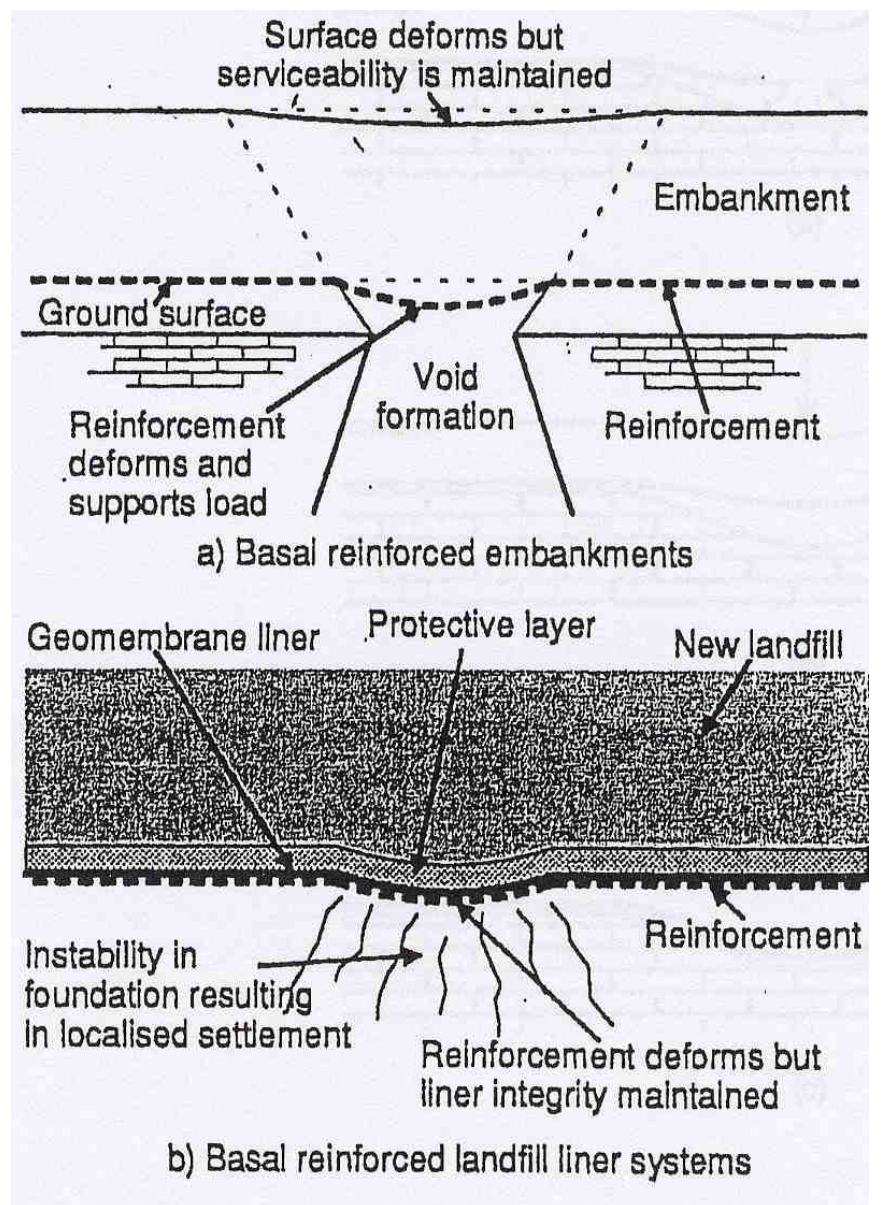

Figure 4. Use of reinforcement to span voids 


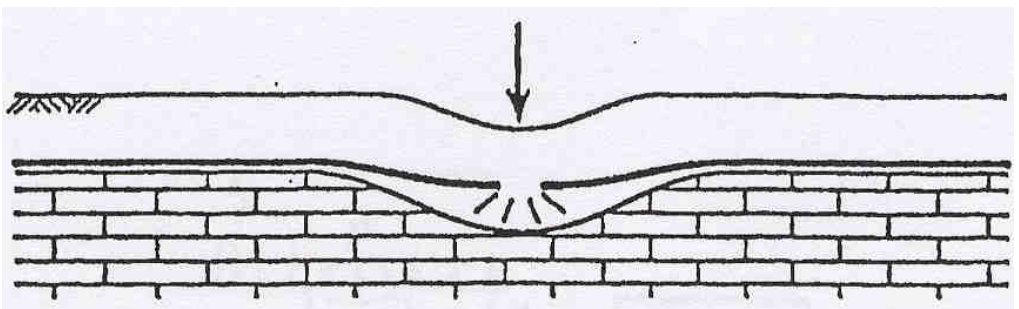

(a)

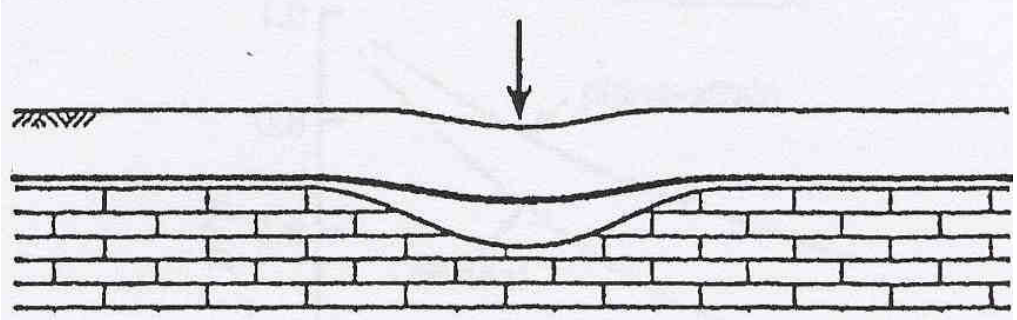

(b)

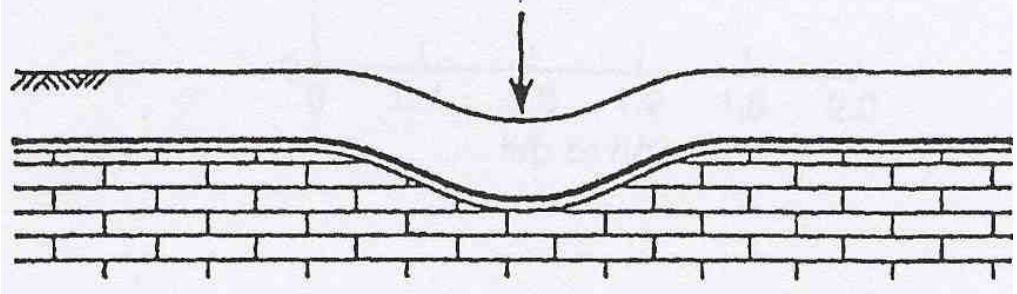

(c)

Figure 5. Action of reinforcement spanning a void 


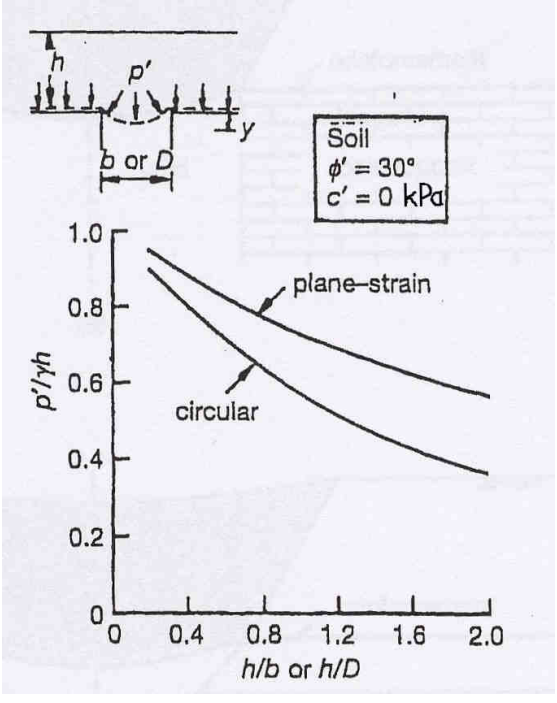

Figure 6. Theoretical reduction in vertical stress due to cohesionless soil arching over an infinitely long void of width $\mathrm{b}(\mathrm{m})$ or a circular void of diameter $\mathrm{D}(\mathrm{m})$

(After Giroud et al, 1990) 


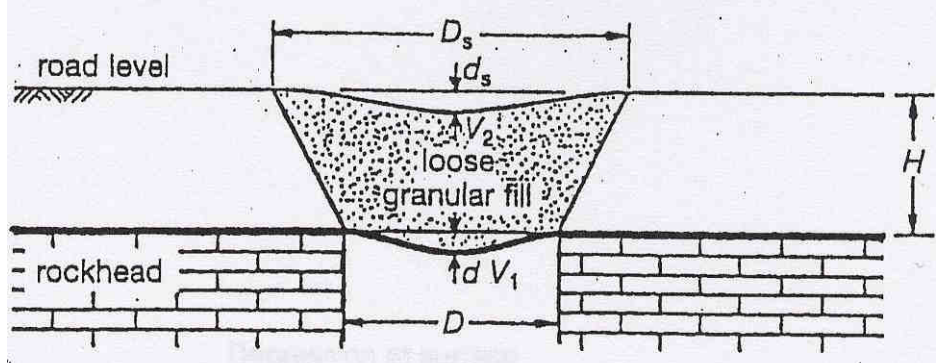

(a)

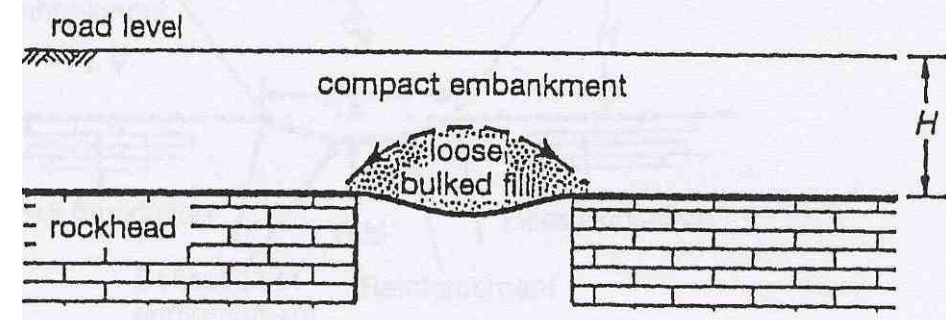

(b)

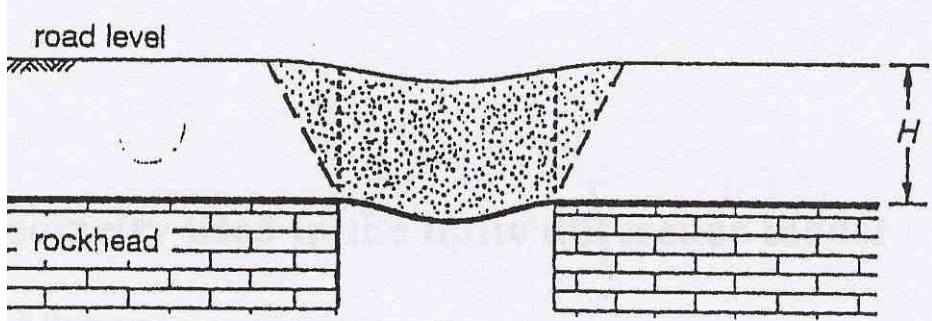

(c)

Figure 7: Tension membrane theory

(a) assumed working condition - arching action assumed in determining tension in reinforcement

(b) actual working condition - arching action assumed

(c) ultimate condition - no arching action 


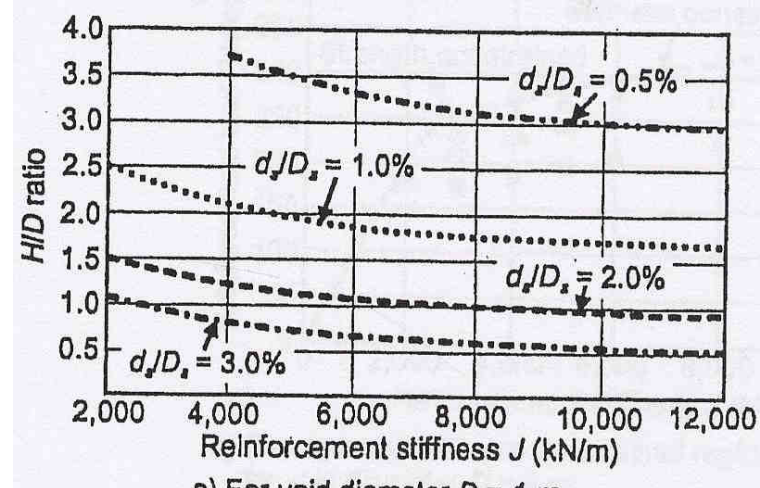

a) For void diameler $D=1 \mathrm{~m}$

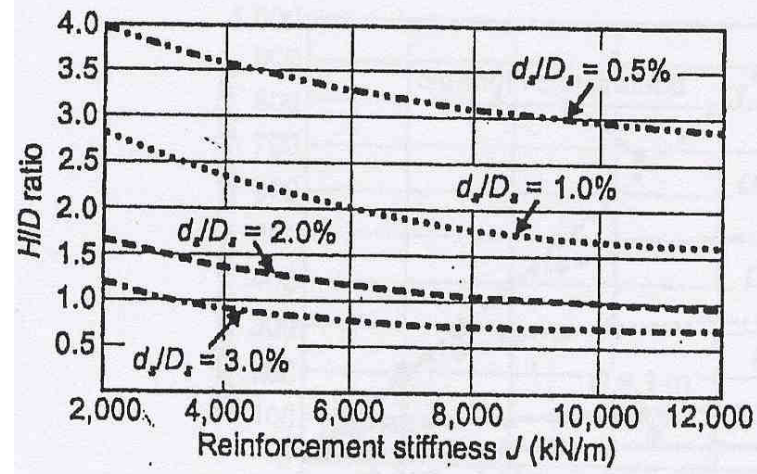

b) For void diameter $D=4 \mathrm{~m}$

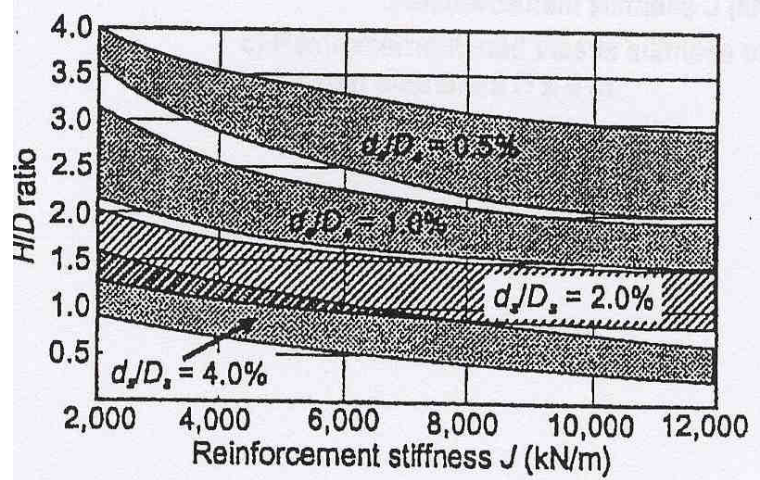

c) For all void diameters less than or equal to $8 \mathrm{~m}$

Figure 8. Effect of reinforcement stiffness on surface differential deformation

(After Lawson et al, 1994) 


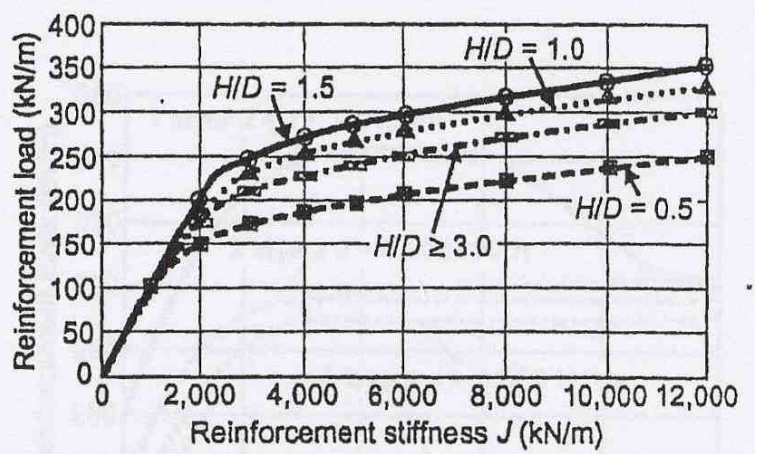

a) Load in reinforcement for void diameter $D=4 \mathrm{~m}$

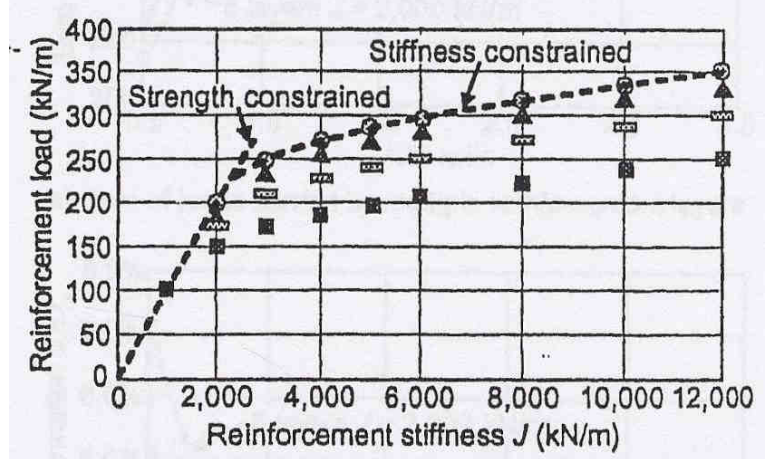

b) Strength and stiffness constrained regions at $H I D=1.5$ for void diameter $D=4 \mathrm{~m}$

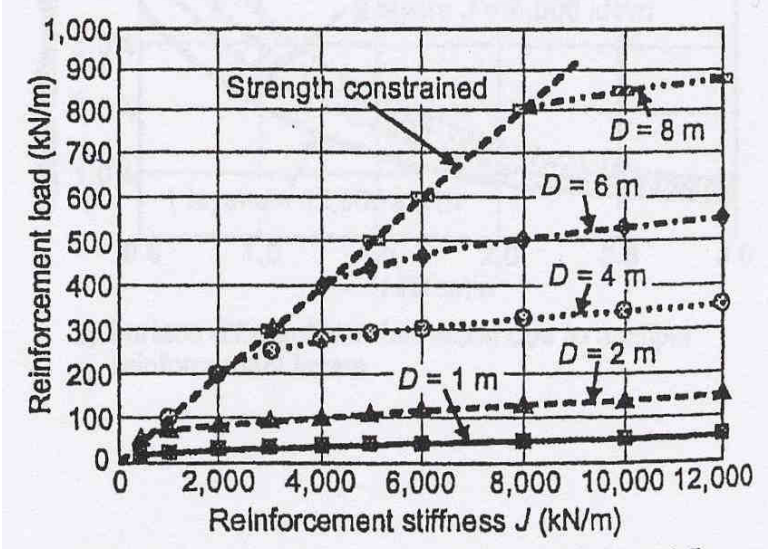

c) Reinforcement load versus stiffness at $H I D=1.5$ for void diameters $D \leq 8 \mathrm{~m}$

Figure 9. Effect of reinforcement stiffness on reinforced load 


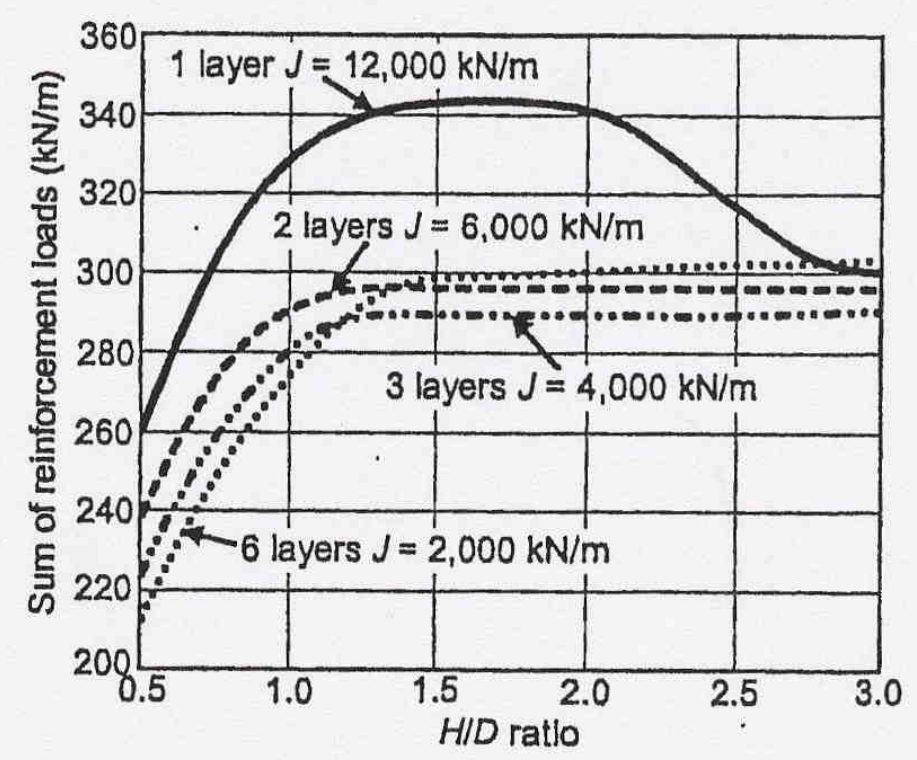

a) Sum of loads carried by multiple reinforcement layers

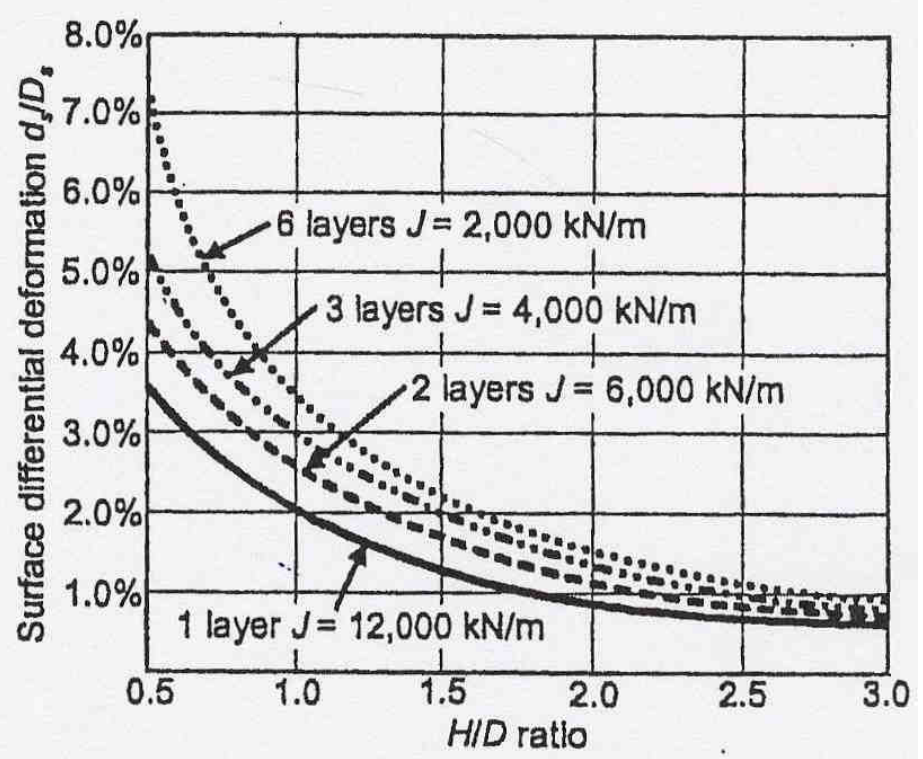

b) Surface differential deformation due to multiple reinforcement layers

Figure 10. Effect of multiple reinforcement layers on structural performance for void diameter $\mathrm{D}=4 \mathrm{~m}$ 